\title{
DISCI.AIMER
}

\begin{abstract}
This report whs prepured as un hecount of work :ponsoret by an ugency of the United Stutes (iovernment. Neither the United Silules (iovernment nor uny ugency thereof, nor uny of their enıployees, mikkes uny wurrunty, express or implied, or aswumes any legul liubility or renponsihility for the Hecurac'y, completeness, or unefulnexn of any informulion, uppuratus, product, or proxees discloned, or represents that its use would not infringe privutely owned rights. Reference herein lo uny specific commerciul prouluct, process, ur service hy trulle nume, Irulemurh. misnufacturer, or wherwise does not necessarily constitute or imply lts endorsement, recont mendution, or fuvoring hy the (Iniled s'tules fiovermulent or uny ugency thereof. The views und upinions of unthors expressed hereen don now necessurily stule or reflect thuse of the Uniled Situles (iwvernment or uny ugenty therent.
\end{abstract}




\section{SIMULATIONS OF COLLISIONLESS SHOCKS}

Kevin B. Quest

Los Alamos National Laboratory, Los Alamos, NM. 87544

\section{ABSTRACT}

A problem of critical importance to space and astrophysics is the existence and propertles of hlgh-Mach-number (HMN) shocks. In this letter we present the results of simulations of perpendicular shocks with Alfuén Mach nimber 22. We thow that the shock structure is a onsitive function of resistivity, becoming turbulent when the resistivity is too low. We discuss the problem of electron heating, and the extension of our results to higher Mach numbers.

\section{INTRODUCTION}

A shock is a nonlinear supersonlc compresilve wave across which ordered flow energy is converted into disordered thermal energy and wagnetic energy. In a coll1sionless shock, the mean free path of lon-electron and electron-electron collisions is very long, so disipation 15 provided by anamolous wave-particle ocatering and ion reflection. The best known example of a collisionless shock 16 the earth's bow shock, formed when the supersontc, super-Alfénic bolar wind runs into the earth's magnetosphere. number shocks produced when an early-type otar f1rst turns on, 2 and the high Mach number shocks driven by supernova reminants. 3

In recent years, the ISEE satelilte program has ot lmulated an intense theoretical and observational program in collisionless shock physics. By combining theory, imulations, and observations, a good underatanding of the Earth's bow shock has emerged but there remain, of course, many unanswered questions. One of the most Important of these 18 the nature of high-Mach-number (HMN) shocks. At present, the fastest shock observed within the solar ayses was al Juplter, and had a magnetosonlc (fast mode) Mach number of 12.4 The lack of higier Mach numbers have led to the ouggestions that (1) there 18 a "2nd criticul" Mach number, above which the shock physics changes radically, or (2) that the golar wind, which generates the planetary bow shocks, rarely exceeds magnetosoni: Mach numbers above 10 .

The Jovian bow shock observed by Russell et al.4 18 displayed in Figure 1. The magnetic field (In units of $y=10^{-5}$ Gauss) 18 plocted as a function $o^{\prime} t$ loe (hours and minutes). Upstream of the -hock ( 1 1ght), the magnet 1c fleld strength 18 less than one $Y$, the plasua $B$ (ratio cf plasma tc magnet1c pressure) 18 2.9, and the shock-normal angle $\theta_{B n} 1878^{\circ}$. The magnetlc fleld at the shock 18 observed to rlse (overshoot) well above 1 ts mean downstream value. 
Particle observations, 5 theory, 6 and amulations 7 have ohown that this overshoot 16 a consequence of a reflected ion beam which 15

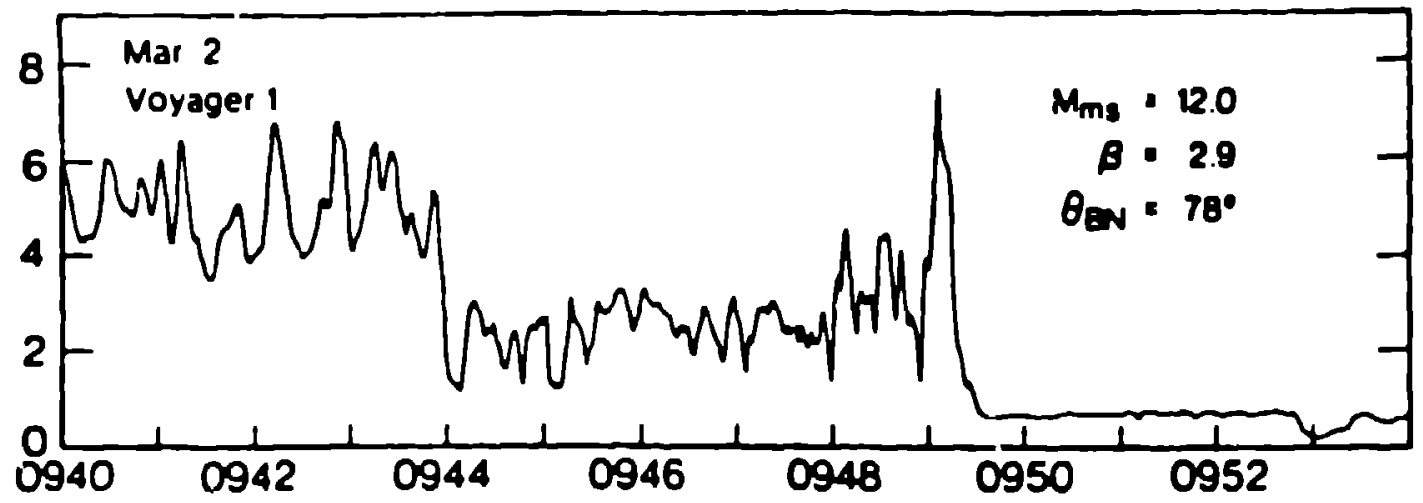

Fig 1. Magnetic fleld $\left(10^{-5} \mathrm{G}\right.$ ) vs. time (hours and minutes) for an outbounu Jovian bow shock crossing (from Ref. 4 ).

the primary source of dissipation for coll1sionless whocks at these Mach numbers.

The etructure of HMN shocks 16 also a toplc of lnterest to astrophysics. Observations of the x-ray emlssions from young super nova remnants show the existance of a well defined opherical shell of hot electrons. ${ }^{6}$ Thls shell 18 belleved to be ine dowristream wake of an outward propagating shock, with Alfven Mach number as high as 1000.9 If true, then there 1s no apparent upper $1101 \mathrm{t}$ to the speed of an ascrophyslcal shock, and addltiunally, ouch shocks etrongly heat the electrons. Predicting how such heating occurs, and what the relative lon to electron temperature rat 10 is downstream of the shock, 18 an unresolved 18 sup of plasma astrophysics.

In thls paper we present numerical simulations of HMN chocks. We review the results of Quest, 10 who showed that in the absence of resistivity HMN shocks are unsteady, and compare these results with shock olmulations including electron dissipation.

\section{SIMULATIONS}

The numerical model we will use 18 one dimensional ( $1 \mathrm{n} x$ ) electromagnet ic hybrid code which follows the individual particle orbits of the lons and treats the electrons as resistive fluld. Because the electrons are wasiess, plasmo oscillations are cuppressed, and the neglect of the displacement current in Ampere" Law eliminates $11 \mathrm{ght}$ waves. As a consequence, large opatial and temporal steps are possible, which allows following the evulution of the shock. for ceveral ion gyroperiods. This wodel has been described In detall prevlously. 19 Plasma 18 co.t Inuously injected from che left-hand boundary $(x-0)$ and woves in the positive $x-$ direction (oer Fig. 2a). When the plasma hita the right-hand boundary $(x-L)$ it la reflected and ahock lo launched (oec Fir. 
2b). As the shock continues to propagate through the box, 1 ts Beparation distance from the wall becomes greater than the downstream ion gyroradius, effectively separating plston and shock heated plasma ( $51 \mathrm{~g} \cdot 2 \mathrm{c})$. The simulation run 16 continued unt 11 the
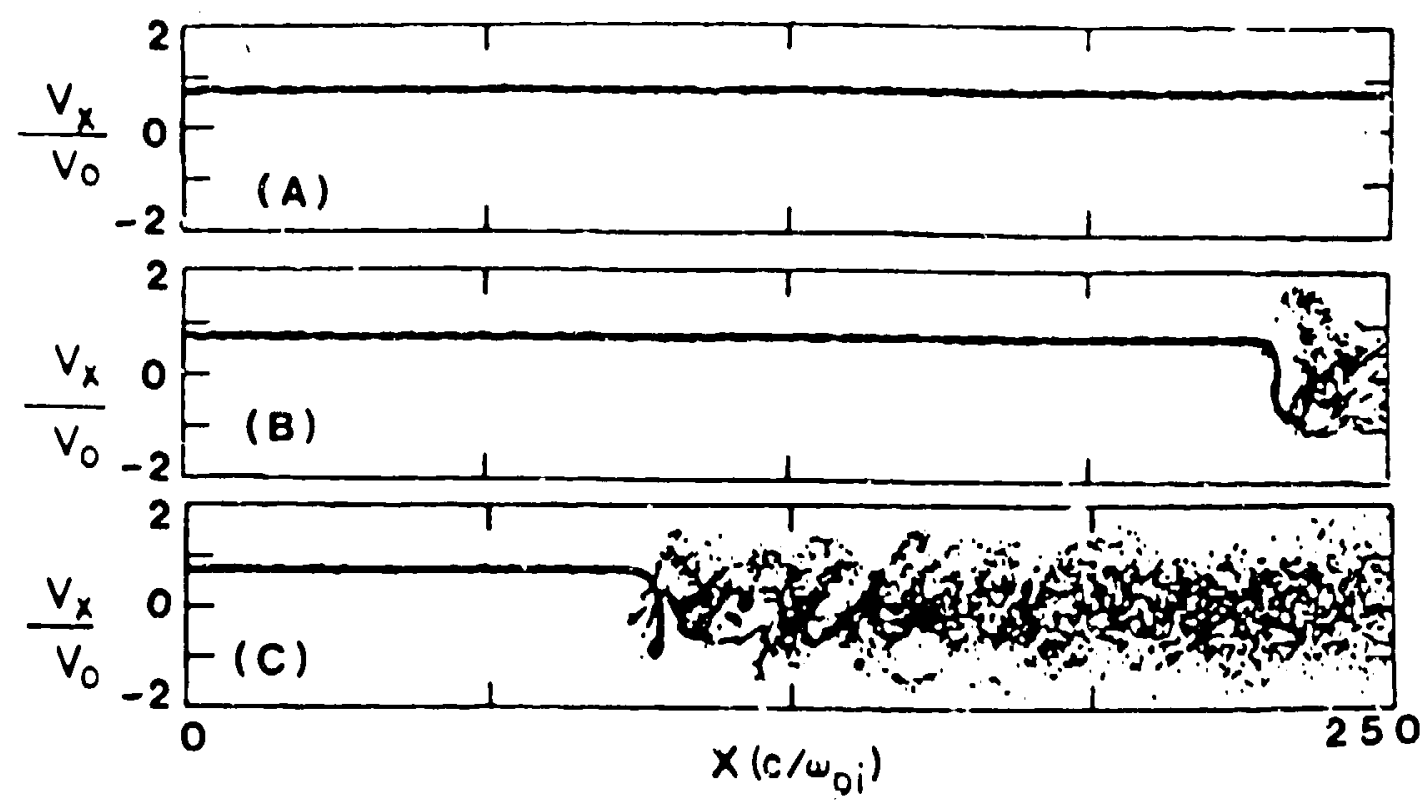

F1g 2. $V_{y}-x$ phase space 1 intelally (A), and at later times (B-r) in the situlation run.

shock generated magnet 16 turbulence decays before reaching the right boundary, Insuring that plston effects do not govern the shock.

- The shock olmulation we will examinelo is perpendicular (B $B, z$ ), propagates at an Alfvén Mach number of 22 , and has an upritream electron nnd 1 on $B$ of 0.5 respectively, where $B$ is the ratio of thermal pressure to magnet $1 \mathrm{c}$ pressure. The upstream rat 10 of Ion plasma frequency $\left(\omega_{-1 / \omega_{1}}\right) 1 \mathrm{~s} 2 \times 10^{4}$ and the resistivity $n$ 16 between $1.5-12 \times 10^{-4} \omega_{p 1}^{p 1}-1$. A check of the aveiage downstram values how that $n_{d} / n_{u} \geq 3, B_{d} / B_{u} \geq 3$ and $T_{1 d} /\left(1 / 2 M_{1} v_{0}^{2}\right) \geq 0.5$ where $u$ denotes upstream, d dowrstream, arid $v$ the shock speed. These results are consistent with the 2-dionensollal Rankine-Hugoniot relations, with wost of the hock energy beling deposited in the 1ons.

Because the shock opeed 1 well above the crltlcal Alfuen Mach number, (approximately 3 for these upstream conditions) dissipation by electron heating alone 1 s Insufficlent to stuf shock steepening. and lon reflection resulta. Slmulatione of esistive perpendicular chocke with $3<M<10$ and $6-1$ have ohown tlat, in this Much rainge, the ahock atructure 1. reasonable eieady. ${ }^{\prime}$ A fraction ot the 
Incoming lons is reflected by a potentlal barrler and magnetic ramp at the shock front. These lons gyrate in front of the shock, gaining energy from the $E \times B$ electric field, and are carried downstream. After thermalizing with the directly transmitted lons, a hoated downstream population results. As the Mach number 16 increased, the reflection process continues to be the dominant source of dissipation, but can be highly oscillatory, depending on the magniture of the resistivity.

If the resistive diffusion length (proportional to the resistivity and inversely proportional to the upstream flow speed) 18 set much saller than a satinl cell size, then 1 t is not possible to stop shock ramp steepening by resistive dissipation. Under these conditions we find that the shock exhibits a perlodicity ( $1 / 3$ of an upstream gyroperlod) in which the shock steepens, breaks and overturns, and then steepens again. Durin: thls cycle, roughly all of the lons are transmltced through the shock, followed by a brief perlod of total reflection.
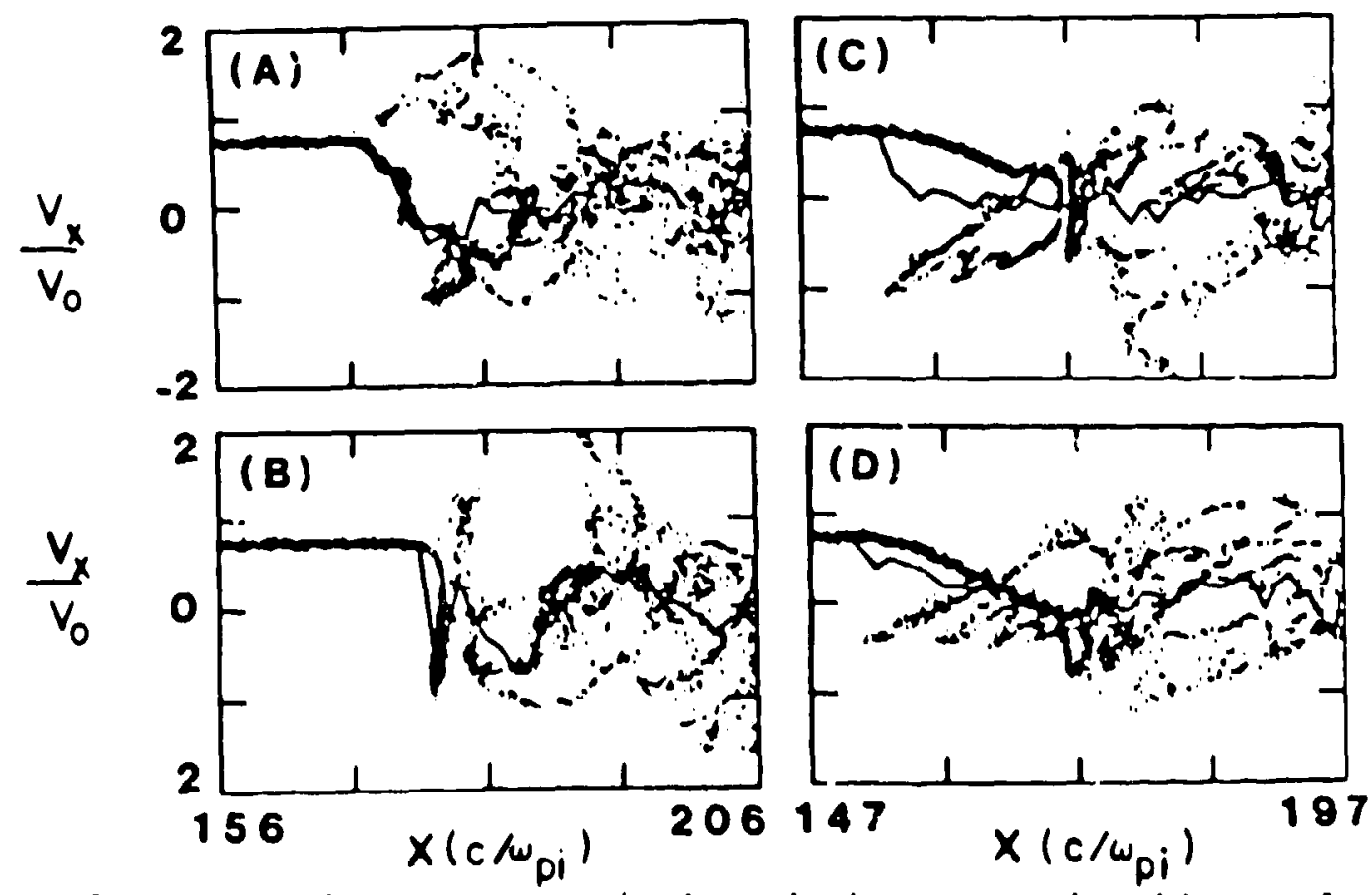

F18 3. $V_{\text {- }}$ - $x$ phase space at 4 timeo during a wave breaking cycle. Resistivity $n 18$ set to 0 for this run.

In F1B. $3 a$ we show a close-up of the $V_{\text {- }}$ - $x$ phase space after the hock has advanced roughly $1 / 3$ of the way into the sluulation box. The colld line 18 the average value of $V$. At this time the chock transition conslsts of amooth ramp. with an energet 1 c 1 on population downstream. The energetic lons are the result of the previous reflection cycle. In F18. 3 b we see the ramp has teepened to 1 to minlmum thickness and 18 otarting to reflect the incowing Ions. In Fig. 3c the lone h. ve been reflected, travel upstream some distance, then turn around and head downstruam. The 
ramp thickness is now very broad and in completing the cycle will steepen because of an E fleld which accelerates particles in the negative $x$ direction. This returns us to $3 a$.

The behavior of the shock is very turbulent, and reminiscent of earlier shock studies in which a periodic formation and destruction of the shock was observed. 22 An important difference in our results, however, 18 that the minlmum shock thickness (just before breaking) 18 numerlcally determined by the cell size. There Is no resistive ion scattering or electron inertia in the code, 6 wave steepening cannot be balanced by disperaion or lon diffusion. Thus, our results demonstrate the process by which the shock will heat lons downstream in the absence of anomalous scattering (by wave breaking), but we are unable to predict detalls of the structure such as the magnitude of the turbulent magnet lc overshoot. Such opecifics will require 2-dimensional particle codes, which include both cross-flejd instablities and electron inertia.

(a)
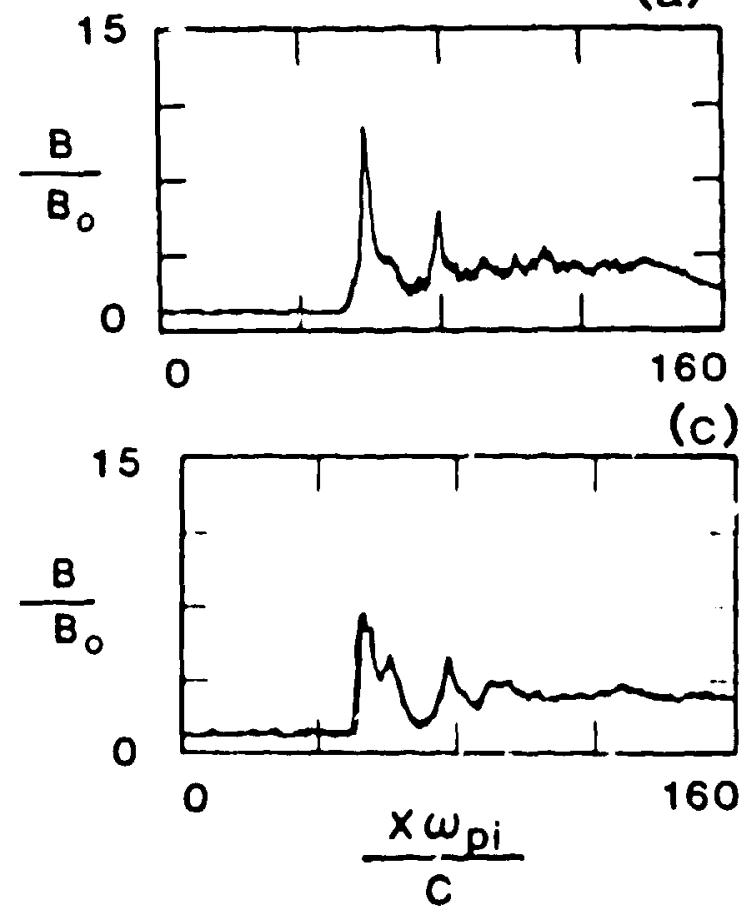

(b)

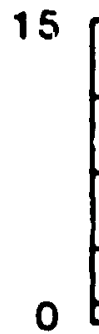

(1)

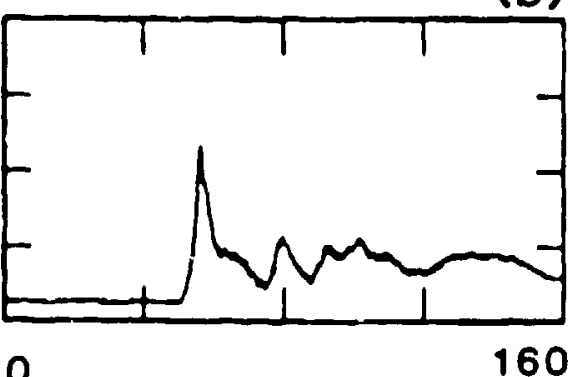

15

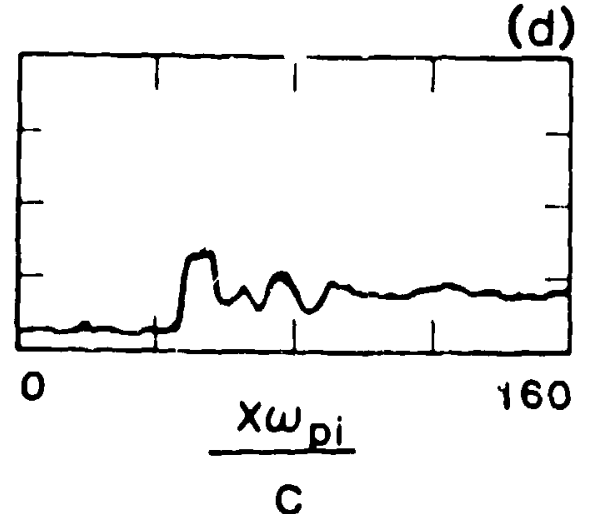

F1g 4. B - - $\mathrm{x}$ plots for four different values $-g^{f} n=$ (A) $1.5 \times 10^{-4}$, (B) $3 \times 10^{-4}$, (C) $6 \times 10^{-4}$, and (D) $1.2 \times 10^{-3}$.

As the resietive diffusion length is increased to a magnituse greater than a cell ize, the temporal behavior of the shock becomes much quieter. In 1 gure 4 a and $4 b$ we show the magnet $1 \&$ flelg profile tor runs with the resistivity set at 1.5 and $3 \times 10^{-4}$ $w^{-1}$. While the wagnet lc overshoots are large ( $\sim 0$ times the upgtream value 114 a), they are quite stationary, varying by less 
than $6 \%$ during the course of the run. These results indicate that there exists range of finlte resistivity over which otationary solutions, simllar to those examined by Leroy et al, at lower Mach numbers. In fact, a simple set of fump conditions, with the fraction of reflected lons set as a free parameter, yleld predictions quite similar to the above two runs. As the resistivity is increased further, the average magnetic overshoot and the fraction of reflected lons continue to decrease (eee Fig. $4 c, 4 i$ ), but the magnitude of RMS deviations increase strongly ( $15 \%$ for the magnet1c overshoot). The problem 18 that increasing the resistivity decreases the fraction of the reflected 1ons. In order to maintain a steady btate the additional disipation must come from the heated electrons. There 18 a $11 \mathrm{mlt}$, however, to the amount of total electron heating (see for example, arguments in Lezoy et $a 1 .{ }^{7}$ ). When the mean number of reflected lons becomes too small, the shock structure osc11lates.

\section{CONCLUSIONS}

Given the various classes of olutions for high-Mach number shocks, which will actually spply? The answer to that question w1ll depend on the efflciency of wave-particle instabilities heating the shocked plasmas. Observatlonally, most shocks with plasma $B=1$ appear quite stationary, even at the higher Mach nuwbers. By contrast, shocks with $B \gg 1$ are very unsteady. 13 It is tempting to speculate that in the former case ( $B=1$ ), the lower-hybrid drift instablity acts to smooth the shock structure, whlle in the latter ( $B \gg 1$ ), the mode 16 stablilied, resulting in cyclic shock steepening and wave breaking. An observational study is currertly in progress to resolve these-ssues. 14 is the Mach number continues to Increase, so does the amount of resistivity required to malntaln a specified shock ramp thickness. It seems 11 kely that for sufficlently fast shocks the resistluity w11l not keep up, and wave breaking will result. Anothez important polnt is that because of the one-dimensionality of the slmulation and the suppression of short-waveleng:h osclllations the thermallzation of the downstream shocked plasma is likely to be quite dizferent from what has been presented here. Since the g: cational energy is perpendicular to the B Cleld, andotropy driven ion Instabilities w1ll generate large fluctuating flelds. Current driven modes and beam modes could be destablilied, pesking at short wavelengths and driving the electrons resistive. For extremely high Mach numbers, the large fluctuat ing flelds generated by the ion anlsoiropy could be absorbed by the resistive electrons, resulting in strong electron heating. Clearly, a greas deal of work 18 required to clarify these and other $188 \mathrm{su}$ ralsed by these 8 lmulations.

Th1s work was supported by NASA Solar Terrestrlal Theory Grant 10-23727 and the U.S. Department of Energy. The autinor would $11 \mathrm{ke}$ to acknowledge useful comments by D. Winske, C. Goodrich, end D. Foralund on an earlier version of this manuscript. 


\section{REFERENCES}

1. N. F. Ness, C. S. Scearce, and J. B. Seek, J. Geophys. Res., 69, $3531(1964)$

2. L. Spltzer, in Physical Processes in the Interstellar Medium, (W1ley, New York, 1978).

3 R. McCray, and T. P. Snow, Ann., Rev. Astron. Astrophys. 17, $213(1979)$.

4. C. T. Russe11, M. N. Hoppe, and W. A. Livsey, Nature 296, 45 (1982).

5. N. Sckopke, G. Paschmann, S. J. Bame, J. T. Gosllikg, and C. T. Russell, J. Geophys. Res. 88, 6121 (1983).

6. M. M. Leroy, Phys. Flu1ds 26, 2742 (1983).

7. M. M. Leroy, D. Winske, C. C. Goodrich, C. S. Wu, and K. Papadopoulos, J. Geophys. Res. 87, 5081 (1982); D. W. Forslund, K. B. Quest, J. U. Brackb111, and K. Lee, J. Geophys. Res. 89, 2142 (1984).

8. A. R. Bell, MRAS 179, 573 (1977).

9. C. F. Mckee ard D. J. Hollentach, Ann. Rev. Astron. Astrophys. 18,219 (1980).

10. K. B. Quest, Fhys. Rev. Lett. 54,1872 (1985).

11. D. WInske and M. M. Leroy, In Compiter Simulations of Space Plasmas, edited by H. Matsumoto and T. Sato (Reldel, Boston, 1985).

12. D. Blskamp and H. Welter, Nucl. Fuslon 12, 663 (1972).

13. V. Formisano, C. T. Russell, J. D. Means, E. W. Greenstadt, F. L. Scarf, and M. Neugebauer, J. Geophys. Res. 80, 2013 (1975).

14. D. Winterhalter (private communication). 